\title{
Chercher à faire revivre des espèces disparues?
}

\section{Jean Martin}

Dr méd., membre de la rédaction

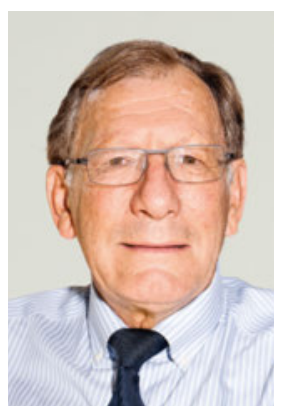

Les potentialités qu'apportent les avancées de la science, notamment en génétique, alimentent nombre d'idées nouvelles voire de fantasmes, par exemple transhumanistes. Dans cet éventail, un supplément du Hastings Center Report [1] est consacré à une problématique concernant la nature - ou la création, telle qu'elle est et telle qu'elle a été: tenter de faire revivre des espèces éteintes?

Beaucoup sont préoccupés par les données montrant que la biodiversité diminue rapidement - des scientifiques parlent de la disparition de 150 espèces par jour (parmi lesquelles, selon eux, certaines disparaissent avant même d'avoir été identifiées, cataloguées). Même si au cours de l'évolution il y a toujours eu émergence d'espèces nouvelles et extinction d'autres, il est pour le moins souhaitable que cet appauvrissement soit freiné. NB: il y a là un rapport avec la notion d'ère anthropocène (les effets marqués et rapides des technologies sur les équilibres vitaux permettent de comparer les phénomènes actuels aux changements qui, dans les ères antérieures, prenaient des centaines de millions d'années). Parmi les moyens de modifications structurelles, il faut considérer l'édition du génome, qui fait envisager un «impact orchestré sur l'évolution biologique» (sic), et le clonage. Dans les perspectives potentielles, il y a l'idée (attrayante en soi) de "ressusciter» des espèces disparues - qui vivaient à la préhistoire mais aussi dans l'histoire parfois récente $\left(19^{\mathrm{e}}\right.$ et $20^{\mathrm{e}}$ siècles). Parmi les animaux d'une certaine taille, on citera l'aurochs, le grand pingouin, le vison marin, le dodo de l'île Maurice, le tigre de Tasmanie, etc.

Question posée par la publication discutée ici: quelle devrait être la position des "conservationnistes» [2] dans ce débat? Donner leur aval éthique aux efforts de «dé-extinction» ou, dans l'optique de ne pas interférer indûment avec la nature telle qu'elle est aujourd'hui, s'y opposer? L'Union internationale pour la conservation de la nature (basée à Gland, Vaud) a émis en 2016 un document de principes (guidelines) en la matière elle ne prend pas position pour ou contre de telles tentatives mais formule des règles à suivre, selon les cas, pour en décider. Intéressant de se demander sur quelles raisons on se baserait pour choisir les cas qui «méritent» d'être ramenés de la mort - de l'extinction. On pourra ne pas vouloir ressusciter des espèces considérées comme nuisibles, mais qui décidera du caractère nuisible, sur quels critères? Modifier certaines espèces pour les rendre utiles (à qui?); les réorienter dans leur écosystème ou dans un écosystème différent? Qui sait si alors elles pourront y (re)trouver leur place? Pour prendre des exemples qui jouiraient d'une certaine sympathie chez de vieux enfants comme moi, nostalgiques de romans situés dans la préhistoire, on pense au mammouth [3], à l'aurochs (pour lequel des tentatives de «backbreeding» sont en cours à partir de matériel bovin). Ou, bien plus près de nous, à une sousespèce de l'lbex d'Espagne (cousin de notre bouquetin), disparu il y a des siècles pensait-on, dont on a retrouvé quelques individus dans une vallée perdue au $20^{\mathrm{e}}$ siècle mais qui n'a plus été revu depuis 2000.

Débats éthiques ardus en perspective. Réfléchir à la question souvent posée actuellement: s'agissant de la vie, l'Homme est-il une créature ou un créateur, ou les deux? Discuter de notre conception de la nature, que certains voudraient immuable mais qui ne l'est à l'évidence pas (certains affirment aujourd'hui «la nature n'existe plus!» - sous forme originale); de la place, de la dignité, accordée aux espèces vivantes non humaines, éteintes ou existantes; de ce qui serait manipulation motivée par hubris «scientifique» ou désir légitime de maintenir voire recréer de la biodiversité. Avec comme toujours la question «Où sont les priorités?».

Et je n'aborde même pas les financements nécessaires. Combien d'argent consacrer à "ressusciter» des espèces animales, végétales voire humaines... (tribus disparues du Nouveau Monde?), plutôt que chercher les voies et moyens de soulager les problèmes de violence et de guerre, de faim et d'aliénation de ceux qui vivent ici et maintenant. Brave New World, de plus en plus...

\section{Références}

1 Hastings Center Report, July-August 2017, vol. 47, Supplement S2. En particulier Kaebnick G.E., Jennings B. De-Extinction and Conservation, pages S2-S4.

2 Militants de la protection des espèces.

3 Voir l'ouvrage de Beth Shapiro «How to clone a mammoth - The science of de-extinction», Princeton University Press, 2015. 